The importance of flavins or flavoproteins in many responses of organisms to light is becoming apparent, and the much debated alternative, carotene, is on the retreat, in such examples as the flagellar response of Euglena, and the development of the coleoptile of oat seedlings. Flavoproteins also appear to provide an explanation for the various 'blue-light effects' in mitochondria, Neurospora and the alga Protosiphon botryoides. In several cases there is clear evidence that the flavin is coupled to an electron transport system, such as a b-cytochrome or plastocyanin. In these examples the metabolic links between the action of the pigments and the observed effects on the organisms were relatively obscure; however, in photosynthesis there have been impressive developments in metabolism. These cover both the chloroplast-cytoplasm relationship of the normal (C3) system and the agriculturally-wasteful process of photorespiration. H. R. Bolhar-Nordenkampf (The University, Vienna) described techniques of measuring photosynthesis and photorespiration in crop leaves, from which the behaviour and future yield of the crop could be assessed. The possibility of photorespiration being an essential detoxification system for the various oxide radicals continues to be discussed.

The subject very clearly divides between the above 'natural, positive' aspects, and the adventitious and negative effects of light, particularly ultraviolet. Although there is considerable data on the effects of ultraviolet on proteins and nucleic acids, the carcinogenic action on human skin could not be simply explained. A more satisfactory molecular explanation could be claimed concerning the success in treating certain skin diseases such as psoriasis and mycosis fungoides with psoralens (which bind to DNA) and UV-A light (M. A. Pathak, Harvard Medical School). Not only ultraviolet, but visible light was clearly shown by J. Marshall (Institute of Ophthalmology, University of London) to lead to striking degradation of retinal cones in animals and people subjected to artificially extended daylength.

The contribution of photobiology to economic problems occupied much attention, in that in principle solar energy remains the one large source of energy available for immediate use. Biological conversion was discussed by D. O. Hall (King's College, London) who pointed out that in many areas existing knowledge and technology could provide not only increased food crops but materials such as ethanol and glycerol at competitive prices. In several cases it had been shown that producing crops under cover in large areas with varied $\mathrm{CO}_{2}$ levels not only relieves losses by photorespiration, but also increases nitrogen fixation and water economy. W. J. Oswald (University of California, Berkeley) is of course unchallengeable in his presentation of algal sewage-farming at a profit. A. A. Krasnovsky (Academy of Sciences, Moscow) and others set out possible photoconversion systems based on isolated pigments or stabilised membrane systems, provided with enzyme systems, for the production of hydrogen. It remained doubtful, however, whether simulated photosynthesis for the production of, essentially, heat would be competitive with existing 'solar panels' for heating (and refrigerating). The discussion of this topic (as Porter had the opportunity to point out in the Farrington-Daniel memorial lecture) has had a phenomenal growth rate in the past four years, and raised Photobiology to the status of a political issue.

\section{Sicily as the sum of parts}

\section{from Peter J. Smith}

The notion that Sicily straddles lithospheric plates is by now a familiar one. The crystalline massif forming the extreme northeast of the island is a continuation of the Calabrian metamorphic belt and thus linked geologically with Europe. The Ragusa carbonate platform in the extreme southeast, on the other hand, is an extension of the Sahara platform and thus linked geologically with Africa. The boundary between the African and European plates (see McKenzie, Geophys. J., 30, 109; 1972) probably runs along the northern edge of Sicily, except in the east where it lies south of the massif.

This interpretation places the resedimentation basin and nappes which form the western and central parts of the island firmly on the African plate. Indeed, Barberi et al. (Earth planet. Sci. Lett., 22, 123; 1974) were apparently able to confirm this when they showed palaeomagnetically that, the crystalline northeast apart, Sicily has been part of the African plate since the Cretaceous. But as might be expected from Sicily's marginal position, things may not be that simple. Caire (in Gravity and Tectonics, Wiley, 1973), for example, has suggested that there may have been a second intra-island plate boundary isolating the Ragusa platform-a possibility apparently not excluded by the work of Barberi and his colleagues who analysed rocks only from the extreme east.

To test this idea, Schult (Earth planet. Sci. Lett., 31, 454; 1976) has now carried out a palaeomagnetic study of Upper Cretaceous and Middle Jurassic volcanic rocks from the west of Sicily. The two poles thus obtained are not only significantly different from those of comparable ages for Europe (as expected) but are even further removed from those for Africa and the Ragusa platform. Since the Upper Cretaceous, westerncentral Sicily has apparently rotated clockwise by about $90^{\circ}$ with respect to southeastern Sicily (and hence with respect to Africa) and by about $60^{\circ}$ with respect to stable Europe.

Schult admits that the margin of error on his results is larger than one would wish; but taken at face value the new poles confirm Caire's proposal that western-central Sicily and the Ragusa platform once behaved as, or as part of, separate crustal blocks. And implicit in that confirmation is western-central Sicily's unique sense of rotation. All other known crustal block rotations in the central Mediterranean were apparently anticlockwise.

A hundred years ago
ARE WE DRYING UP?
Such is the title of a paper in the
September number of the American
Naturalist, by Prof. J. D. Whitney, the
object of which is to bring together
some of the more striking facts in
regard to the desiccation of the earth's
surface-or at least of a considerable
portion of it-which has taken place in
the most recent geological period, and
to suggest the inquiry whether we have
any proof that this desiccation has been
and is continued into the historical
period: in short, Are we drying up?
There is a prevailing popular im-
pression that the countries around the
Mediterranean are drier than they were
two or three thousand years ago, and
that this change is due in part, if not
wholly, to the cutting down of the
forests which are assumed to have once
existed there. Yet, when this matter
comes to be investigated, it would
appear that there is little if any evi-
dence either that there has been any
such wholesale stripping of wooded
lands, or that there has been any con-
siderable change in the climate of that
region.
From Nature, 14, October 12 , 527;
1876.
and

